\title{
SISTEMAS DE MANEJO EM PLANTIOS FLORESTAIS DE EUCALIPTO E PERDAS DE SOLO E ÁGUA NA REGIÃO DO VALE DO RIO DOCE, MG
}

\author{
MANAGEMENT SYSTEMS IN THE EUCALYPTUS FOREST PLANTATIONS AND \\ THE SOIL AND WATER LOSSES IN VALE DO RIO DOCE, MG STATE
}

\author{
Mayesse Aparecida da Silva ${ }^{1}$ Marx Leandro Naves Silva ${ }^{2}$ Nilton Curi ${ }^{2}$ \\ Junior Cesar Avanzi ${ }^{3}$ Fernando Palha Leite ${ }^{4}$
}

\begin{abstract}
RESUMO
A erosão hídrica é a principal responsável pela perda da capacidade produtiva dos solos sob florestas plantadas e alteração da quantidade e qualidade da água em sub-bacias. Assim, este trabalho objetivou avaliar a influência dos sistemas de manejo adotados nos plantios florestais com eucalipto (eucalipto em nível - EN, eucalipto em desnível - ED e eucalipto em desnível com queima - EDQ) sobre as perdas de solo e água por erosão hídrica em relação às perdas em floresta nativa (FN), pastagem (PP) e solo descoberto (SD), num Latossolo Vermelho (LV) e Latossolo Vermelho-Amarelo (LVA), e indicar qual o período mais crítico no manejo do solo, em relação à erosão hídrica, durante o ciclo de cultivo do eucalipto. O estudo foi conduzido em dois municípios: Belo Oriente (LVA) e Guanhães (LV), situados no Vale do Rio Doce, região Centro-Leste do estado de Minas Gerais. Com exceção do sistema SD no LVA, as perdas de solo foram abaixo do limite de tolerância admissível para essas classes de solos, nestas regiões, que são de 11,22 Mg $\mathrm{ha}^{-1}$ ano $^{-1}$ no LV e de 7,17 Mg ha ${ }^{-1}$ ano $^{-1}$ para o LVA. As perdas de água nos sistemas com eucalipto foram menores no plantio em nível, no LVA. Nos sistemas com eucalipto, os períodos iniciais após o plantio apresentam as maiores perdas de solo e água com redução ao final do ciclo. Por outro lado, no LVA os sistemas com solo descoberto e floresta nativa apresentaram aumento das perdas de água com o decorrer do tempo avaliado, indicando adequação dos sistemas com eucalipto.
\end{abstract}

Palavras-chave: erosão hídrica; potencial erosivo da chuva; sedimento; escoamento superficial.

\section{ABSTRACT}

Water erosion is the main responsible for decreasing the productive capacity of soils under forest plantations and it changes the amount and the quality of water in sub-basins. Thus, this work aimed to evaluate the influence of management systems adopted in Eucalyptus forest plantations (eucalyptus in contour planting - EN, eucalyptus up and downslope planting - ED, and eucalyptus up and downslope planting with burning - EDQ) on soil and water losses by water erosion and to compare them with losses in native forest (FN), pasture (PP) and bare soil (SD), in a Red Latosol (LV) and Red-Yellow Latosol (LVA), indicating which is the most critical period in relation to water erosion during the cycle of Eucalyptus forest plantation. The study was carried out in two places: Belo Oriente (LVA) and Guanhães (LV), located in 'Doce' River Valley, central and eastern region of Minas Gerais State, Brazil. Except for the SD system in the LVA, the average soil losses were below the limit of soil loss tolerance, in such regions, which are $11.22 \mathrm{Mg} \mathrm{ha}^{-1} \mathrm{yr}^{-1}$ for the LV and 7.17 Mg ha-1 $\mathrm{yr}^{-1}$ for the LVA. The water losses in the eucalyptus systems were lower in the contour planting, in the LVA. In the eucalyptus systems, the periods immediately after planting showed the greatest soil and water losses with reduction at the final period. On the other hand, in the LVA, the bare soil and native forest systems increased water losses with the advancing of the evaluation period, indicating

1. Engenheira Florestal, MSc., Doutoranda pela Universidade Federal de Lavras, Caixa Postal 3037, CEP 37200000, Lavras (MG). Bolsista da CAPES. mayesse@gmail.com

2. Engenheiro Agrônomo, Dr., Professor do Departamento de Ciência do Solo, Universidade Federal de Lavras, Caixa Postal 3037, CEP 37200-000, Lavras (MG). Bolsista do CNPq. marx@dcs.ufla.br / niltcuri@dcs.ufla.br

3. Engenheiro Agrícola, Dr. Pesquisador da Embrapa Pesca e Aquicultura, Palmas, TO. junior.avanzi@embrapa.br

4. Engenheiro Agrônomo, Dr., Pesquisador da Empresa CENIBRA S.A., Caixa Postal 100, Bairro Horto, CEP 35162970, Ipatinga (MG). fernando.leite@cenibra.com.br

Recebido para publicação em 12/04/2010 e aceito em 13/09/2010 
adequacy of Eucalyptus systems.

Keywords: water erosion; erosive potential of the rain; sediment; runoff.

\section{INTRODUÇÃO}

Minas Gerais é o estado com maior área de florestas plantadas no Brasil (CELULOSE ONLINE, 2009), sendo que a maior parte desses plantios concentra-se nas regiões do Vale do Rio Doce, Centro-Oeste, Noroeste, Centro-Norte e Vale do Jequitinhonha/Mucuri (MINAS GERAIS, 2008).

A região do Vale do Rio Doce, atualmente, é uma das regiões mais degradadas pela erosão hídrica no estado de Minas Gerais. Essa região foi submetida a um impactante efeito antrópico nos últimos $50-60$ anos, que incluiu: desmatamento da floresta nativa, uso indiscriminado do fogo e manejo incorreto das pastagens e total desrespeito à capacidade de suporte das pastagens, o que aliado ao relevo movimentado dominante e à ocorrência de chuvas erosivas concentradas resultou num quadro dramático de degradação do solo, decorrente do processo de erosão acelerada inclusive no topo dos morros (áreas de recarga do lençol freático).

Normalmente, os plantios florestais encontram-se inseridos em ecossistemas sensíveis às perturbações antrópicas em função de razões como o relevo acidentado, solos com baixa fertilidade natural e antigas áreas agrícolas degradadas. Estes fatores associados às operações de manejo, colheita mecanizada da madeira, construção e manutenção de estradas florestais e ao potencial erosivo da região são os principais responsáveis pela perda da capacidade produtiva dos solos sob florestas plantadas e alteração da quantidade e qualidade da água em sub-bacias, decorrentes da erosão hídrica. Em média, cerca de 30\% dos sedimentos perdidos por erosão hídrica chegam aos mananciais, podendo comprometer a qualidade da água e causar assoreamento (HERNANI et al., 2002). Com a adoção de práticas conservacionistas consegue-se minimizar as perdas de solo e água, garantindo uma produção com menor impacto ao meio ambiente e menor custo. De acordo com Dechen et al. (1981), Eltz (1984), Rufino et al. (1985), Nunes Filho et al. (1990), Margolis et al. (1991), Silva et al. (1992), Bono et al. (1996), Seganfredo et al. (1997), Santos et al. (1998), Cassol et al. (1999), Hernani et al. (1999), Levien e Cogo (2001), Beutler et al. (2003), Cogo et al. (2003), Leite et al. (2004), Guadagnin et al. (2005), Cullum et al. (2007) e Amaral et al. (2008), os preparos conservacionistas, que além do plantio em nível utilizam pequena movimentação mecânica do solo e sistemas de manejo que proporcionam eficiente cobertura vegetal são os que apresentam menores perdas de solo e água por erosão hídrica.

Visando identificar os níveis de perdas de solo e água em sistemas florestais, estudos têm sido conduzidos. Entre eles, estão os trabalhos de Lima (1988) que, com o crescimento da floresta, observou diminuição do escoamento superficial e da perda de solo das parcelas florestadas em relação à parcela com solo descoberto, que continuou apresentando taxas elevadas de escoamento superficial e de erosão. Vital et al. (1999) observaram que, apesar de os valores de perdas de um Argissolo VermelhoAmarelo terem praticamente dobrado no primeiro ano após o corte raso de eucalipto em uma subbacia, os valores de $0,04 \mathrm{Mg} \mathrm{ha}^{-1}$ por ano foram ainda significativamente menores do que os decorrentes do uso mais intensivo do solo. Martins et al. (2003), Martins (2005), Pires et al. (2006) e Oliveira (2008) quantificaram perdas de solo para o eucalipto próximas da mata nativa indicando sustentabilidade daquele ambiente no contexto da erosão hídrica. Estudos de perdas de solo e água em plantios de Acacia mangium, com duração de doze meses, conduzidos em Roraima, concluíram que as maiores perdas de solo e água foram observadas na fase de estabelecimento dos plantios, antes do fechamento das copas. A cobertura vegetal mais densa dos plantios de acácia foi o fator que mais contribuiu para redução das perdas de solo por erosão; o plantio de acácia a favor do declive, comum na região, contribuiu para o aumento da enxurrada em curto prazo, favorecendo com isso as perdas de solo por erosão hídrica (BARROS et al., 2009).

Os objetivos deste trabalho foram avaliar a influência dos sistemas de manejo adotados nos plantios florestais com eucalipto sobre as perdas de solo e água por erosão hídrica, compará-los às perdas em floresta nativa, pastagem e solo descoberto, num Latossolo Vermelho e Latossolo Vermelho-Amarelo; e indicar qual o período mais crítico no manejo do solo, em relação à erosão 
hídrica, durante o ciclo de cultivo do eucalipto.

\section{MATERIAL E MÉTODOS}

$\mathrm{O}$ estudo foi realizado em áreas experimentais de plantios de eucalipto, localizadas em dois municípios: Belo Oriente, situado nas coordenadas UTM 764566 de longitude E e 7872916 de latitude S e Guanhães nas coordenadas UTM 717932 de longitude E e 7922802 de latitude S (Datum SAD 69), ambos situados no Vale do Rio Doce, região Centro-Leste do estado de Minas Gerais.

O clima da região de Belo Oriente é Aw, tropical com inverno seco e estação chuvosa no verão, segundo classificação de Köppen, com temperatura média anual variando entre $22^{\circ} \mathrm{C}$ e $27^{\circ} \mathrm{C}$, sendo a máxima de $32^{\circ} \mathrm{C}$ e a mínima de $18^{\circ} \mathrm{C}$. A precipitação média anual varia de 701 a $1.500 \mathrm{~mm}$ e altitude média de $300 \mathrm{~m}$. Na região de Guanhães o clima é Cwa, com inverno seco e verão chuvoso, segundo classificação de Köppen, e temperatura média anual variando de $18^{\circ} \mathrm{C}$ a $22^{\circ} \mathrm{C}$. A precipitação pluviométrica média anual é de $1.181 \mathrm{~mm}$ e altitude média de $850 \mathrm{~m}$. Os solos, onde se encontram as parcelas experimentais, foram classificados como Latossolo VermelhoAmarelo Distrófico típico textura muito argilosa (LVA) e Latossolo Vermelho Distrófico típico textura muito argilosa (LV) respectivamente para Belo Oriente e Guanhães (CENIBRA, 2001). A avaliação dos atributos mineralógicos e físicos foi realizada nos perfis de solo utilizados para caracterização e classificação dos mesmos sob mata nativa e podem ser vistos na Tabela 1 . A tolerância de perdas de solo por erosão hídrica admissível, nas regiões, é de 7,17 $\mathrm{Mg} \mathrm{ha}^{-1} \mathrm{ano}^{-1}$ para o LVA (PIRES, 2004) e de $11,22 \mathrm{Mg} \mathrm{ha}^{-1} \mathrm{ano}^{-1}$ no LV (SILVA et al., 2002).

O ciclo de cultivo do eucalipto para celulose, nestas regiões, leva em média 6,5 anos. A implantação deste experimento foi feita no $4^{\circ}$ ciclo, sendo que os plantios foram realizados em outubro de 2002 adotando-se o cultivo mínimo com espaçamento de $3,0 \times 3,3 \mathrm{~m}$ em covas manuais, cujas dimensões foram $30 \times 30 \times 30 \mathrm{~cm}$ e realizado o corte raso em março de 2009. Neste estudo, foram utilizados dados de perdas de solo e de água ocorridos no período de outubro de 2002 a dezembro de 2008 , os quais corresponderam a 1 ciclo de cultivo do eucalipto. Os sistemas de manejo adotados nos plantios de eucalipto nas duas regiões constituíram de plantio em nível sem queima de restos culturais
(EN), plantio no sentido do declive sem queima de restos culturais (ED) e plantio no sentido do declive com queima de restos culturais (EDQ). Estes sistemas foram comparados ao sistema de referência (floresta nativa - FN), ao sistema de uso comum na região (pastagem plantada de Brachiaria sp. - PP) e ao sistema de máxima perda de solo e água (solo descoberto - SD), o qual após a última colheita do eucalipto teve os resíduos vegetais retirados da área e, mantido continuamente descoberto (Tabela 2). Sempre que necessário era realizado uma capina na parcela mantida sobre o solo descoberto para controle da vegetação espontânea.

Para determinação do potencial erosivo da chuva $\left(\mathrm{EI}_{30}\right)$, foram acumulados os dados diários de precipitação pluvial para Belo Oriente e Guanhães, MG, extraídos do banco de dados Hidroweb da Agência Nacional de Águas (ANA, 2009). A precipitação mensal foi constituída do somatório das precipitações diárias que ocorreram em determinado mês. Dessa forma, puderam ser obtidos os valores mensais da precipitação pluviométrica, para todos os meses de todos os anos da série.

TABELA 1: Atributos mineralógicos e físicos na profundidade de $0-20 \mathrm{~cm}$.

TABLE 1: Mineralogical and physical attributes 0-20 cm deep.

\begin{tabular}{lll}
\hline Atributo & $\begin{array}{l}\text { Latossolo } \\
\text { Vermelho- } \\
\text { Amarelo }\end{array}$ & $\begin{array}{l}\text { Latossolo } \\
\text { Vermelho }\end{array}$ \\
\hline $\mathrm{Ct}\left(\mathrm{g} \mathrm{kg}^{-1}\right)$ & 380 & 364 \\
$\mathrm{~Gb}\left(\mathrm{~g} \mathrm{~kg}^{-1}\right)$ & 117 & 162 \\
$\mathrm{~Gb} / \mathrm{Gb}^{\mathrm{C}} \mathrm{Ct}$ & 0,24 & 0,31 \\
$\mathrm{SiO}\left(\mathrm{g} \mathrm{kg}^{-1}\right)$ & 116,4 & 177,2 \\
$\mathrm{Fe}_{2} \mathrm{O}_{3}\left(\mathrm{~g} \mathrm{~kg}^{-1}\right)$ & 77 & 69 \\
$\mathrm{Fe}(\mathrm{DCB})\left(\mathrm{g} \mathrm{kg}^{-1}\right)$ & 8,94 & 63,44 \\
$\mathrm{Fe}(\mathrm{oxalato})\left(\mathrm{g} \mathrm{kg}^{-1}\right)$ & 1,82 & 3,18 \\
Areia total $\left(\mathrm{g} \mathrm{kg}^{-1}\right)$ & 322 & 310 \\
Areia muito grossa $\left(\mathrm{g} \mathrm{kg}^{-1}\right)$ & 11 & 17 \\
Areia grossa $\left(\mathrm{g} \mathrm{kg}^{-1}\right)$ & 42 & 69 \\
Areia média $\left(\mathrm{g} \mathrm{kg}^{-1}\right)$ & 82 & 106 \\
Areia fina $\left(\mathrm{g} \mathrm{kg}^{-1}\right)$ & 166 & 101 \\
Areia muito fina $\left(\mathrm{g} \mathrm{kg}^{-1}\right)$ & 21 & 17 \\
Silte $\left(\mathrm{g} \mathrm{kg}^{-1}\right)$ & 53 & 101 \\
Argila $\left(\mathrm{g} \mathrm{kg}^{-1}\right)$ & 624 & 589 \\
Densidade do solo $\left(\mathrm{g} \mathrm{cm}^{-3}\right)$ & 1,24 & 1,1 \\
Densidade de partículas $\left(\mathrm{g} \mathrm{cm}^{-3}\right) 2,5$ & 2,39
\end{tabular}

Em que: $\mathrm{Ct}=$ caulinita; $\mathrm{Gb}=$ gibbsita. 
TABELA 2: Localização das parcelas padrão experimentais de perdas de solo e água com diferentes sistemas de manejo em Belo Oriente (LVA) e Guanhães (LV), MG.

TABLE 2: Location of the experimental soil and water losses standard-erosion plots with different management systems in the Belo Oriente (LVA) and Guanhães (LV), MG.

\begin{tabular}{|c|c|c|c|c|c|c|}
\hline \multirow[t]{2}{*}{ Sistemas } & \multicolumn{4}{|c|}{ Coordenadas (UTM 23K SAD 69) } & \multicolumn{2}{|c|}{ Declividade (\%) } \\
\hline & & & $\mathrm{L}$ & & LVA & LV \\
\hline FN & $7869089 \mathrm{~S}$ & $771974 \mathrm{E}$ & $7939341 \mathrm{~S}$ & $715580 \mathrm{E}$ & 42,4 & 26,8 \\
\hline PP & $7867827 \mathrm{~S}$ & $776104 \mathrm{E}$ & $7936481 \mathrm{~S}$ & $714540 \mathrm{E}$ & 24,9 & 19,4 \\
\hline $\mathrm{EN}$ & $7851910 \mathrm{~S}$ & $772622 \mathrm{E}$ & $7939994 \mathrm{~S}$ & $714894 \mathrm{E}$ & 34,4 & 17,6 \\
\hline ED & $7868522 \mathrm{~S}$ & $772842 \mathrm{E}$ & $7939996 \mathrm{~S}$ & $714919 \mathrm{E}$ & 30,6 & 17,6 \\
\hline EDQ & $7868491 \mathrm{~S}$ & $772900 \mathrm{E}$ & $7939988 \mathrm{~S}$ & $714869 \mathrm{E}$ & 36,4 & 17,6 \\
\hline SD & $7868272 \mathrm{~S}$ & $775176 \mathrm{E}$ & $7939987 \mathrm{~S}$ & $714842 \mathrm{E}$ & 32,5 & 17,6 \\
\hline
\end{tabular}

Em que: $\mathrm{LVA}=$ Latossolo Vermelho-Amarelo; $\mathrm{LV}=$ Latossolo Vermelho; $\mathrm{FN}=$ Floresta nativa; $\mathrm{PP}=$ Pastagem plantada; EN = Plantio de eucalipto em nível; ED = Plantio de eucalipto no sentido do declive sem queima de restos culturais; $\mathrm{EDQ}=$ Plantio de eucalipto no sentido do declive com queima de restos culturais; $\mathrm{SD}=$ Solo descoberto. Fonte: Oliveira (2006).

Para se obter uma estimativa aproximada do índice de erosividade mensal, foi determinado o coeficiente da chuva, conforme proposto por Fournier (1956) e modificado por Lombardi Neto (1977):

$$
R_{c}=p^{2} \times P^{-1}
$$

Onde: Rc é o coeficiente de chuva ( $\mathrm{mm}$ ), $\mathrm{p}$ é a precipitação média mensal $(\mathrm{mm})$ e $\mathrm{P}$ é a precipitação média anual $(\mathrm{mm})$. A erosividade da chuva pôde, então, ser obtida através das equações (2) e (3) respectivamente para Belo Oriente e Guanhães, conforme Silva et al. (2010):

$$
\begin{aligned}
& E I_{30}=215,4 \times R_{c}^{0,65} \quad \mathrm{R}^{2}=0,89 \\
& E I_{30}=123,34 \times R_{c}^{0,74} \quad \mathrm{R}^{2}=0,95
\end{aligned}
$$

Tais equações permitiram obter valores mensais do índice $\mathrm{EI}_{30}$, para as séries históricas de precipitação pluvial das regiões de Belo Oriente e Guanhães, MG.

Considerando o efeito da cobertura vegetal como amenizante do processo erosivo, a avaliação das perdas de solo foi dividida em 3 períodos: Período 1, considera os anos de 2003 e 2004, que são os primeiros anos de implantação da cultura do eucalipto; Período 2, considera os anos de 2005 e 2006; e Período 3, considera os anos de 2007 e 2008. Nesta etapa, o ano de 2002 não foi considerado por ser o início do experimento. Sugere-se eliminar os dados do primeiro ano em estudos desta natureza devido à grande movimentação do solo no momento de montagem das parcelas, variabilidade da umidade antecedente do solo e outros fatores experimentais, ocasionando altas perdas de solo para valores baixos de erosividade e vice-versa (McGREGOR et al. 1969; SILVA et al., 1997). O monitoramento das perdas de solo e água foi realizado por meio de parcelas padrão instaladas no campo com dimensões de 4 x $24 \mathrm{~m}$ (solo descoberto, floresta e pastagem) sendo que as parcelas com eucalipto tiveram sua largura multiplicada por $3 \mathrm{em}$ razão do espaçamento desta cultura, garantindo assim, dentro da parcela um maior número de plantas, avaliando de maneira mais eficiente o efeito da proteção pelo dossel desta cultura. Em razão das dificuldades de implantação e condução de experimentos dessa natureza como distância do experimento da sede de trabalho, recursos humanos e financeiros e tempo, foram observadas 12 parcelas, cada uma delas correspondendo a um tratamento, sem repetição, conforme observado em outros trabalhos (LIMA, 1988; ALBUQUERQUE et al., 2002; COGO et al., 2003; MARTINS et al., 2003; AMARAL et al., 2008).

As parcelas foram contornadas com chapas galvanizadas de $40 \mathrm{~cm}$ de largura, enterradas a uma profundidade de $20 \mathrm{~cm}$. Na parte inferior das parcelas foram colocadas calhas coletoras para conduzirem a enxurrada até os tanques coletores. A estrutura coletora foi constituída de um tanque de sedimentação, munido de um divisor do tipo Geib de 15 janelas, e um tanque coletor. A partir do sistema divisor tipo Geib, através de uma canaleta, a água e sedimentos correspondentes à vazão de uma janela foram conduzidos para o tanque coletor. Assim, 
após o enchimento do tanque de sedimentação, 1/15 de água da enxurrada era conduzida ao segundo tanque e o restante (14/15) retornava ao ambiente. A amostragem de sedimentos para quantificação das perdas de solo e água foi realizada para cada evento de chuva seguindo o procedimento descrito por Cogo (1978). Após cada evento de precipitação foi medida a altura da enxurrada dentro dos tanques de coleta e sedimentação. Em seguida, realizou-se uma homogeneização da enxurrada coletada pelos tanques e retiraram-se três alíquotas de volume representativo predeterminado. As amostras foram transferidas para o laboratório para o processamento gravimétrico. Primeiramente, as amostras foram floculadas com uma solução saturada de sulfato de alumínio. Após decantação dos sedimentos, drenouse o sobrenadante, e o material decantado foi levado à estufa a uma temperatura de $105^{\circ} \mathrm{C}$ até peso constante. $\mathrm{O}$ cálculo das perdas de solo foi realizado para cada evento de chuva, sendo expresso em $\mathrm{kg}$ $\mathrm{ha}^{-1}$.

\section{RESULTADOS E DISCUSSÃO}

\section{Perdas médias de solo e água}

As perdas médias de solo apresentaram amplitude de $8,2 \mathrm{~kg} \mathrm{ha}^{-1}$ ano $^{-1}$ (FN) a $4.872 \mathrm{~kg}$ $\mathrm{ha}^{-1} \mathrm{ano}^{-1}(\mathrm{SD})$ no LV e de $58,1 \mathrm{~kg} \mathrm{ha}^{-1} \mathrm{ano}^{-1}(\mathrm{EN})$ a $17.417,2 \mathrm{~kg} \mathrm{ha}^{-1}$ ano $^{-1}$ (SD) no LVA (Tabela 3 ). Com exceção do sistema SD no LVA, as perdas de solo foram abaixo do limite de tolerância admissível para essas classes de solos, nestas regiões, que são de $11.220 \mathrm{~kg} \mathrm{ha}^{-1}$ ano $^{-1}$ no LV (SILVA et al., 2002) e de $7.170 \mathrm{~kg} \mathrm{ha}^{-1} \mathrm{ano}^{-1}$ para o LVA (PIRES, 2004). Martins (2005) verificou valores de perdas de solo na ordem de 1 a $66.370 \mathrm{~kg} \mathrm{ha}^{-1} \mathrm{ano}^{-1} \mathrm{em}$ parcelas com eucalipto (Plintossolo Háplico) e solo descoberto (Argissolo Amarelo). Comparando-se os valores médios anuais de perdas de solo da parcela com eucalipto plantado em nível e a parcela com solo descoberto, constata-se uma redução em torno de $99 \%$ para as duas classes de solo. A mesma redução foi encontrada por Albuquerque et al. (2002), os quais compararam solo descoberto com caatinga nativa em Luvissolo Hipocrômico órtico vértico.

Analisando os sistemas com eucalipto e a PP, houve perdas médias maiores na PP para as duas classes de solo, exceto no sistema EDQ no LVA, sugerindo que o uso do solo com eucalipto, nesta região, garante melhor proteção ao solo que o uso da pastagem e evidenciando o efeito negativo da queimada na proteção do solo contra a erosão hídrica. Na região amazônica, Barbosa e Fearnside (2000) quantificaram perdas de solo 7,5 vezes maior para pastagens com $B$. humidicola em relação à floresta primária.

Entre os sistemas com eucalipto a ordem das perdas de solo obedeceu à sequência: ED > $\mathrm{EDQ}>\mathrm{EN}$ para o LV e EDQ $>\mathrm{ED}>\mathrm{EN}$ para o LVA. Estes resultados mostram a importância do uso de práticas conservacionistas, como o plantio em nível, na redução da erosão hídrica, corroborando com resultados obtidos por Margolis et al. (1985), Bertoni e Lombardi Neto (1985), Silva et al. (1989), Margolis et al. (1991) e Albuquerque et al. (2002). Outro fator importante na redução das perdas de solo nos sistemas com eucalipto está ligado ao sistema de preparo do solo adotado, que foi o cultivo mínimo, o qual consiste em revolver o solo o mínimo necessário, mantendo os resíduos vegetais sobre o mesmo com cobertura morta, evitando que este fique descoberto nos primeiros anos de plantio (MARTINS, 2005) e favorecendo a agregação do solo. Brito et al. (2005) e Pires et al. (2006) encontraram correlação significativa entre diâmetro médio geométrico dos agregados (DMG) sem pré-umedecimento e as perdas de solo em Latossolos dessa região, o que indica a influência destes atributos no processo de erosão hídrica, sendo este fato evidenciado na diferença de perdas de solo

TABELA 3: Perdas médias de solo, para cada sistema de manejo, durante o período de 2002 a 2008.

TABLE 3: Average soil losses for each management system, during the period from 2002 to 2008.

\begin{tabular}{|c|c|c|c|c|c|c|c|}
\hline \multirow[b]{2}{*}{ Solo } & \multirow[b]{2}{*}{$\mathrm{EI}_{30}$} & \multicolumn{6}{|c|}{ Perdas de solo } \\
\hline & & SD & FN & PP & EDQ & ED & EN \\
\hline & & ---------- & --- & $--\mathrm{kg} \mathrm{h}$ & $\mathrm{O}^{-1}---$ & 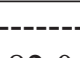 & - \\
\hline Latossolo Vermelho & 10.745 & $4.872,0$ & 8,2 & 851,3 & 34,4 & 82,0 & 30,5 \\
\hline Latossolo Vermelho-Amarelo & 10.693 & $17.417,2$ & 67,5 & 249,1 & 490,0 & 99,1 & 58,1 \\
\hline
\end{tabular}

Em que: $\mathrm{EI}_{30}=$ Potencial erosivo da chuva em $\mathrm{MJ} \mathrm{mm} \mathrm{ha}^{-1} \mathrm{~h}^{-1} \mathrm{ano}^{-1} ; \mathrm{SD}=$ Solo descoberto; $\mathrm{FN}=$ Floresta nativa; $\mathrm{PP}=$ Pastagem plantada; $\mathrm{EDQ}=$ Plantio de eucalipto no sentido do declive com queima de restos culturais; $\mathrm{ED}=$ Plantio de eucalipto no sentido do declive sem queima de restos culturais; EN = Plantio de eucalipto em nível. 
entre o LV e o LVA, em que o LVA apresentou DMG menor (BRITO et al., 2005; PIRES et al., 2006) e perdas de solo maiores que o LV (Tabela 3). Silva et al. (1998) verificaram 99,6\% de redução nas perdas de solo para o sistema corte raso de acácia-negra e deposição de seus resíduos, quando comparado ao sistema corte raso e queimada dos resíduos.

Nas duas classes de solo, o sistema SD apresentou as maiores perdas de solo, enquanto que os sistemas FN e EN tiveram as menores perdas respectivamente para o LV e LVA, sendo que os demais sistemas com eucalipto mostraram perdas de solo intermediárias, corroborando com Oliveira (2008). Estes resultados demonstram a eficiência tanto da floresta nativa, quanto dos plantios com eucalipto em nível, em proteger o solo contra o impacto direto da gota de chuva, reduzindo as taxas de erosão hídrica quando comparado com o solo descoberto. Meeuwig (1970) estudando a ocorrência de erosão hídrica em áreas montanhosas florestadas observou que, dentre inúmeras variáveis estudadas, a proporção de solo protegido contra o impacto direto das gotas das chuvas pela presença da vegetação ou da camada orgânica (serrapilheira) mostrou ser a variável que mais contribuiu para o controle das perdas de solo. Vásquez-Méndez et al. (2010) também relataram o grande efeito benéfico da serrapilheira e da vegetação na redução das perdas de solo e de água na região semiárida do México, chegando a uma redução nas perdas de solo de $55 \mathrm{~kg} \mathrm{ha}^{-1}$ ano $^{-1}$ para cada incremento unitário no índice de cobertura vegetal.

A precipitação média no período deste estudo (2002 a 2008) foi de 1.011 e $1.081 \mathrm{~mm}$, respectivamente no LV e LVA. No LV, para todos os sistemas estudados, as perdas de água variaram de $0,1 \%$ (FN) a $1,2 \%$ (ED) da precipitação média anual, enquanto que no LVA a amplitude foi de 2,6\% (ED e EN) a 16,3\% (SD) (Figura 1). No LVA, com exceção do sistema SD, todos os outros sistemas apresentaram perdas médias de água menores que o sistema FN, o qual é o sistema em equilíbrio, evidenciando que a cobertura do solo proporcionada pela copa das árvores e a formação da serrapilheira contribuem para aumentar a infiltração de água no solo, diminuindo o escoamento superficial.

Entre os sistemas com eucalipto, o sistema que mais perdeu água foi $\operatorname{ED}(1,2 \%)$ e $\operatorname{EDQ}(3,8 \%)$, respectivamente no LV e LVA. Estes valores encontram-se abaixo dos obtidos por Barbosa e Fearnside (2000) na floresta amazônica em Latossolo Vermelho-Amarelo, o qual apresentou perdas de água de 7,4\% em relação à precipitação total. A utilização de práticas conservacionistas como o plantio em nível, reduz as perdas de água ao parcelar o comprimento de rampa, através das curvas de nível, diminuindo a velocidade do escoamento superficial e proporcionando uma maior infiltração de água no solo. Já os sistemas que consideram a queima de resíduos vegetais como prática de limpeza da área têm, como conseqüências, a redução ou eliminação da cobertura vegetal, favorecendo o escoamento superficial da água da chuva e agravando o processo erosivo (SANTOS et al., 1992).

\section{Perdas de solo e água por período}

Para as duas classes de solo o sistema SD foi o que apresentou as maiores perdas de solo em todos os períodos (Tabela 4). O sistema FN nos dois primeiros períodos apresentou perdas menores que os demais sistemas nas duas classes de solo. Esse padrão deve-se ao sistema FN já se encontrar em estado de equilíbrio (clímax), ao passo que os sistemas de eucalipto foram se desenvolvendo com o passar do tempo. No entanto, no último período, que compreende a fase final do ciclo de cultivo do eucalipto, as perdas médias de solo no sistema EDQ foram menores do que no sistema $\mathrm{FN}$ para o LV e LVA, mostrando que os plantios de eucalipto foram eficientes em proteger o solo contra a erosão hídrica. Essa eficiência, notadamente no final do ciclo da cultura, está ligada ao fechamento e entrelaçamento das copas das árvores e formação da serrapilheira que, com o crescimento da floresta, intercepta as gotas de chuva evitando o impacto e o desprendimento e transporte das partículas de solo, além de aumentar a infiltração de água no solo reduzindo o escoamento superficial. Barros et al. (2009) observaram que as maiores perdas de solo e água em plantios de Acacia mangium ocorreram na fase de estabelecimento da cultura, antes do fechamento das copas.

Considerando os sistemas com eucalipto no LV, o período 1 foi o que apresentou as maiores perdas, exceto para o sistema EDQ, o qual teve as maiores perdas no período 2. No LVA, as perdas em todos os períodos foram maiores no EDQ, onde houve queima da camada orgânica protetora do solo, seguido pelos sistemas ED e EN. Este último sistema apresentou as maiores perdas no período 1 , diminuindo até o último período, evidenciando o efeito do desenvolvimento da cultura na redução da erosão hídrica. De acordo com Martins et al. (2003) as perdas de solo e água nos plantios de 


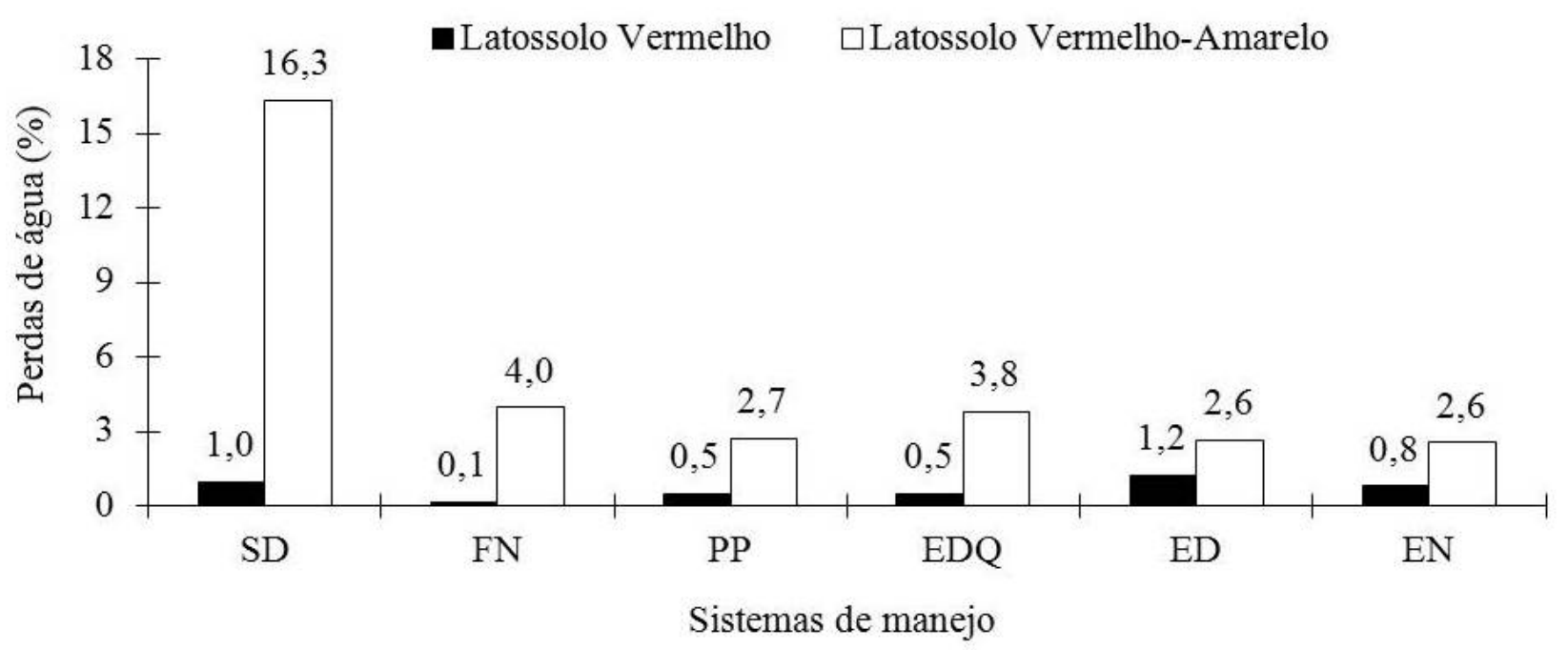

FIGURA 1: Porcentagem das perdas de água em relação à precipitação pluvial média, durante o período de 2002 a 2008. SD: solo descoberto; FN: floresta nativa; PP: pastagem plantada; EDQ: plantio de eucalipto no sentido do declive com queima de restos culturais; ED: plantio de eucalipto no sentido do declive sem queima de restos culturais; EN: plantio de eucalipto em nível.

FIGURE 1: Percentage of water losses in relation to average rainfall, from 2002 to 2008 period. SD: bare soil; FN: native forest; PP: pasture; EDQ: eucalyptus up and downslope planting with burning; ED: eucalyptus up and downslope planting; EN: eucalyptus in contour planting.

TABELA 4: Perdas médias de solo para cada período durante um ciclo completo de cultivo do eucalipto. TABLE 4: Average soil losses for each period of time during a whole cycle of eucalyptus cultivation.

\begin{tabular}{|c|c|c|c|c|c|c|c|c|}
\hline \multirow{2}{*}{ Solo } & \multirow{2}{*}{ Período } & \multirow{2}{*}{$\mathrm{EI}_{30}$} & \multicolumn{6}{|c|}{ Perdas de solo } \\
\hline & & & SD & FN & PP & EDQ & ED & EN \\
\hline & & & -----. & -------- & $-\mathrm{kg} \mathrm{ha}^{-1} \mathrm{p}$ & íodo ${ }^{-1}--$ & -------- & - \\
\hline \multirow{3}{*}{ Latossolo Vermelho } & 1 & 10.772 & $15.474,9$ & 23,1 & $2.254,8$ & 37,6 & 262,5 & 86,4 \\
\hline & 2 & 11.240 & $1.569,2$ & 3,9 & 716,0 & 78,4 & 20,0 & 16,4 \\
\hline & 3 & 8.208 & 3,5 & 1,1 & 2,4 & 0,5 & 1,7 & 3,2 \\
\hline \multirow{3}{*}{ Latossolo Vermelho-Amarelo } & 1 & 11.032 & $32.932,6$ & 71,6 & 104,3 & $1.438,8$ & 247,3 & 149,0 \\
\hline & 2 & 12.211 & $23.595,8$ & 29,2 & 196,5 & 249,3 & 84,5 & 42,5 \\
\hline & 3 & 8.040 & $2.287,5$ & 129,7 & 518,5 & 11,4 & 8,3 & 6,4 \\
\hline
\end{tabular}

Em que: Período 1 = Anos de 2003 e 2004 (primeiros anos de implantação da cultura do eucalipto); Período 2 = Anos de 2005 e 2006; Período 3 = Anos de 2007 e 2008; $\mathrm{EI}_{30}=$ Potencial erosivo da chuva em MJ mm ha ${ }^{-1} \mathrm{~h}^{-1}$ ano $^{-1}$; SD = Solo descoberto; $\mathrm{FN}=$ Floresta nativa; $\mathrm{PP}=$ Pastagem plantada; $\mathrm{EDQ}=$ Plantio de eucalipto no sentido do declive com queima de restos culturais; $\mathrm{ED}$ = Plantio de eucalipto no sentido do declive sem queima de restos culturais; EN $=$ Plantio de eucalipto em nível. 
eucalipto devem diminuir com o avanço da idade, tendência observada por estes autores do terceiro para o quarto ano após o plantio, corroborando com estudos de Lima (1996); Vital et al. (1999) e Oliveira (2008). Nos plantios florestais, as operações de manejo adotadas no preparo do solo e na colheita mecanizada da madeira são as principais causas de degradação do solo (GONÇALVES, 2002). Outro agravante são as queimadas, que têm como consequência a eliminação da cobertura vegetal, favorecendo o escoamento superficial (SANTOS et al., 1992) e afetando negativamente a agregação, estruturação e permeabilidade do solo decorrentes da menor estabilidade dos agregados. Segundo Vital et al. (1999) mesmo tendo dobrado os valores de perdas de solo no primeiro ano após o corte raso da floresta, estes são ainda significativamente menores do que as perdas normalmente observadas decorrentes do uso mais intensivo do solo, como na agricultura, por exemplo.

As maiores perdas de água para o LV foram observadas nos dois primeiros períodos enquanto que, para o LVA, as maiores perdas aconteceram no último período para os sistemas $\mathrm{SD}, \mathrm{FN}$ e $\mathrm{PP}$ e no primeiro período para os sistemas com eucalipto (Figura 2). A falta da cobertura vegetal, aliada às operações de colheita e preparo do solo foram os principais responsáveis pelas maiores perdas

Latossolo Vermelho

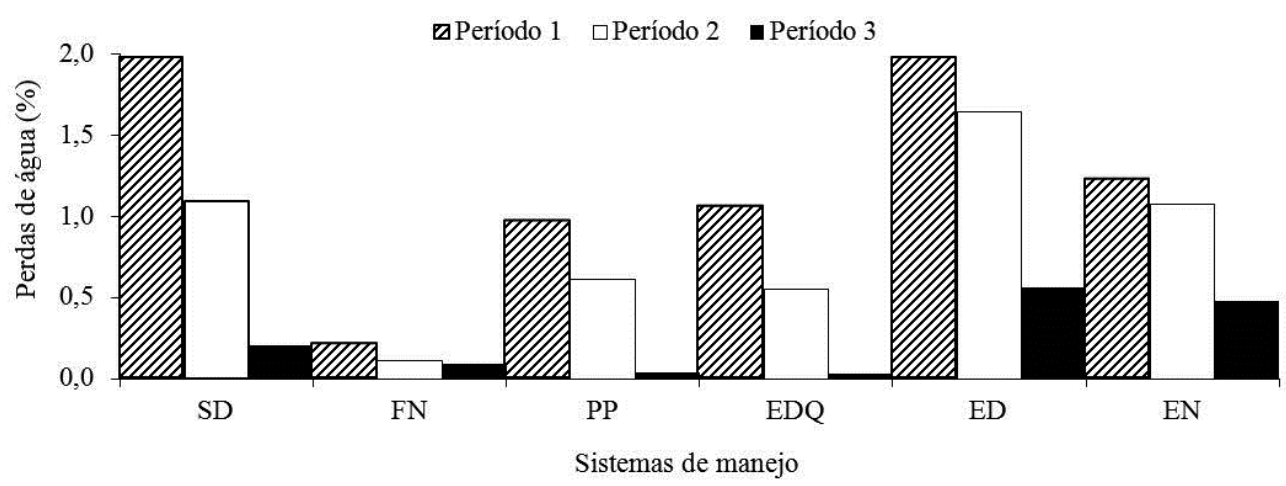

Latossolo Vermelho-Amarelo

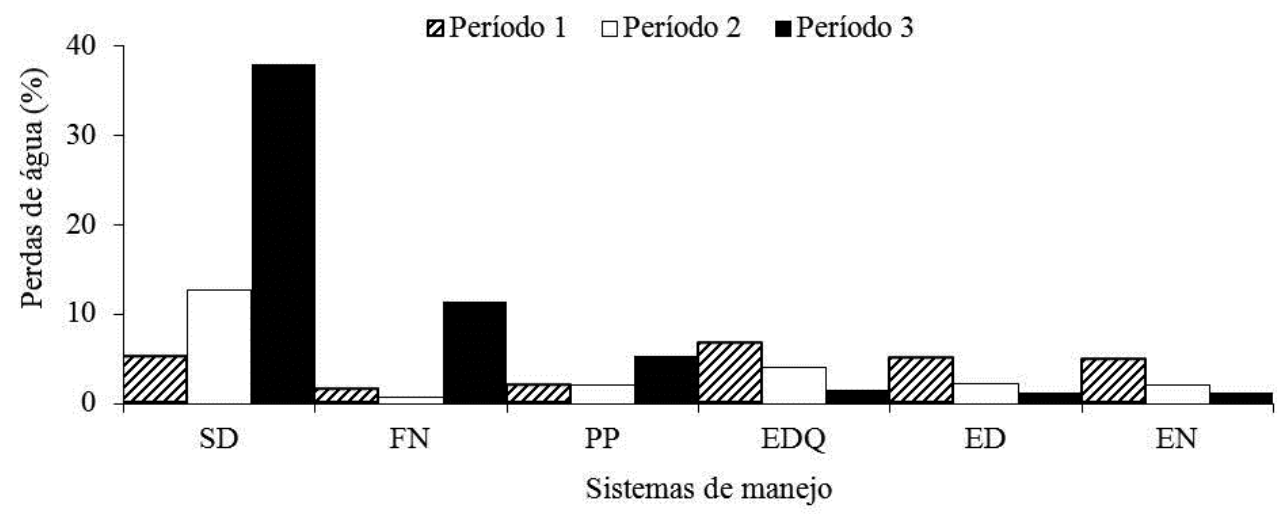

FIGURA 2: Porcentagem das perdas médias de água em relação à precipitação pluvial média para cada período durante um ciclo de cultivo do eucalipto. Período 1: anos de 2003 e 2004 (primeiros anos de implantação da cultura do eucalipto); Período 2: anos de 2005 e 2006; Período 3: anos de 2007 e 2008; FN: floresta nativa; PP: pastagem plantada; EDQ: plantio de eucalipto no sentido do declive com queima de restos culturais; ED: plantio de eucalipto no sentido do declive sem queima de restos culturais; EN: plantio de eucalipto em nível.

FIGURE 2: Percentage of avegare water losses in relation to average rainfall for each period during a whole cycle of eucalyptus cultivation. SD: bare soil; FN: native forest; PP: pasture; EDQ: eucalyptus up and downslope planting with burning; ED: eucalyptus up and downslope planting; EN: eucalyptus in contour planting. 
nos primeiros anos após o plantio. No LV há uma diminuição das perdas de água do período 2 para o período 3 em todos os sistemas estudados. Já no LVA para os sistemas SD e FN houve aumento das perdas de água do período 2 para o 3, ocorrendo a maior perda no SD, o qual correspondeu a $37 \%$ da precipitação total. Lima (1988) observou sensível diminuição das perdas de água e solo em plantios de eucalipto em relação à parcela com solo descoberto, que continuou apresentando taxas elevadas de escoamento e de erosão. Comparando os sistemas com eucalipto e a FN, no LV as perdas nos sistemas com eucalipto, no último período, foram maiores do que na FN, com exceção do sistema EDQ, e no LVA esses valores encontraram-se abaixo da FN.

De modo geral, o LVA teve perdas de solo maiores que o LV, mesmo apresentando potencial erosivo menor (Tabela 3). Esse fato está relacionado à maior declividade em que o LVA se encontra (Tabela 2) e aos atributos diferenciais de cada solo (Tabela 1). Em função do aumento da declividade do terreno aumentam também a velocidade e o volume do escoamento superficial e, consequentemente, o volume de solo e água perdidos por erosão hídrica. O LVA apresenta teores de areia fina e muito fina maiores que o LV, o que confere a esse solo maior capacidade de arraste, uma vez que as partículas mais finas são facilmente transportadas pelo fluxo de água. Segundo Wischmeier e Mannering (1969), a fração areia muito fina tem o comportamento do silte, favorecendo os processos erosivos. O LV apresenta maiores teores de gibbsita e óxidos de ferro, favorecendo uma estrutura mais granular, mais arredondada e com menor tamanho, corroborando com Lima et al. (1990), induzindo uma maior macroporosidade e, consequentemente, maior permeabilidade e maior estabilidade do LV em relação à erosão hídrica. Essa maior estabilidade apresentada pelo LV pode ter sido a principal responsável pela pouca variação entre as perdas médias de solo e água entre os sistemas estudados, mascarando os possíveis efeitos dos tratamentos estudados na erosão hídrica. Resende (1985) relata que os Latossolos da região de estudo apresentam diversos atributos que ajudam a reduzir substancialmente a erosão.

\section{CONCLUSÕES}

Os sistemas com eucalipto apresentam perdas de solo e água abaixo do sistema de máxima perda (Solo Descoberto - SD), indicando que esta cultura, nestas regiões, encontra-se adequada em termos de erosão hídrica, mesmo quando utilizados sistemas não conservacionistas, com exceção do sistema com eucalipto em desnível (ED), no LV, que apresenta perdas de água superiores ao solo descoberto.

A pastagem mostra-se favorável ao controle da erosão hídrica, sendo menos eficiente que o eucalipto na redução das perdas de solo. Contudo, mais promissora na retenção e infiltração de água, exceto para eucalipto com queima de resíduos no LVA.

No geral, o LVA apresenta perdas maiores que o LV, resultantes da maior declividade em que o LVA se encontra e aos atributos diferenciais de cada solo.

Os sistemas com eucalipto apresentam perdas de solo e água maiores nos primeiros anos de sua implantação (período 1) decrescendo durante os anos (período 2), exceto no sistema de eucalipto plantado no sentido do declive e com queima dos restos culturais (EDQ) no LV. Assim, os períodos iniciais após o plantio são os mais críticos, devendose ter maiores cuidados no manejo do solo nesse período.

O sistema com plantio de eucalipto em nível apresenta, no geral, perdas médias de solo e água menores que os outros sistemas com eucalipto, exceto para as perdas médias de água no sistema EDQ e para as perdas de solo e água por período no $\mathrm{LV}$, confirmando a eficiência do uso de práticas conservacionistas, também, em plantios florestais.

\section{AGRADECIMENTOS}

Os autores agradecem à Celulose Nipo Brasileira S. A. (CENIBRA S. A.) e seus funcionários pela condução e coleta de dados das áreas experimentais.

\section{REFERÊNCIAS BIBLIOGRÁFICAS}

ALBUQUERQUE, A. W. et al. Manejo da cobertura do solo e de práticas conservacionistas nas perdas de solo e água em Sumé, PB. Revista Brasileira de Engenharia Agrícola e Ambiental, Campina Grande, v. 6, n. 1, p. 136-141, jan./abr. 2002.

AMARAL, A. J.et al. Redução da erosão hídrica em três sistemas de manejo do solo em um Cambissolo Húmico da região do Planalto Sul-Catarinense. Revista Brasileira de Ciência do Solo, Viçosa, v. 32, n. 5, p. 2145-2155, set./out. 2008. 
ANA - Agência Nacional de Águas. Disponível em: $<$ http://hidroweb.ana.gov.br $>$ Acesso em: 09 de fevereiro de 2009.

BARBOSA, R. I.; FEARNSIDE, P. M. Erosão do solo na Amazônia: estudo de caso na região do Apiaú, Roraima, Brasil. Acta Amazônica, Manaus, v. 30, n. 4, p. 601-613, abr. 2000.

BARROS, L. da S. et al. Perdas de solo e água em plantio de Acacia mangium Wild e Savana em Roraima, norte da Amazônia. Revista Brasileira de Ciência do Solo, Viçosa, v. 33, n. 2, p. 447-454, mar./abr. 2009.

BERTONI, J.; LOMBARDINETO, F. Conservação do solo. Piracicaba: Livroceres, 1985. 368 p.

BEUTLER, J. F. et al. Perdas de solo e água num Latossolo Vermelho aluninoférrico submetido a diferentes sistemas de preparo e cultivo sob chuva natural. Revista Brasileira de Ciência do Solo, Viçosa, v. 27, n. 3, p. 509-517, maio/jun. 2003.

BONO, J. A. M. et al. Cobertura vegetal e perdas de solo por erosão em diversos sistemas de melhoramento de pastagens nativas. Pasturas Tropicales, Cali, v. 18, n. 1, p. 2-8, abr. 1996.

BRITO, L. F.et al. Erosão hídrica de Latossolo Vermelho muito argiloso relevo ondulado em área de pós-plantio de eucalipto no Vale do Rio Doce, região Centro Leste do Estado de Minas Gerais. Scientia Forestalis, Piracicaba, n. 67, p. 27-36, abr. 2005.

CASSOL, E. A. et al. Infiltração de água e perdas de água e solo por erosão influenciadas por diferentes métodos de melhoramento da pastagem nativa Gaúcha. Revista Brasileira de Ciência do Solo, Viçosa, v. 23, n. 4, p. 923-931, set./dez. 1999.

CELULOSE ONLINE. MG lidera tecnologia para florestas plantadas. Disponível em: $<\mathrm{http}: / / \mathrm{www}$. celuloseonline.com.br/pagina/pagina.asp?IDItem= 22849\&IDNoticia $=19262>$. Acesso em: 11 maio 2009.

CENIBRA. Levantamento semidetalhado de solos das regiões do Rio Doce, Cocais, Sabinópolis e Virginópolis. Ipatinga, 2001. v.1, 101 p.

COGO, N. P. Uma contribuição à metodologia de estudo das perdas de solo por erosão em condições de chuva natural: I: sugestões gerais, medição de volume, amostragem e quantidade de solo e água da enxurras $-1^{a}$ aproximação. In: ENCONTRO NACIONAL DE CONSERVAÇÃO DO SOLO, 2., 1978, Passo fundo. Anais... Passo Fundo: EMBRAPA/CNPT, 1978. p. 75-97.

COGO, N. P. et al. Perdas de solo e água por erosão hídrica influenciadas por métodos de preparo, classes de declive e níveis de fertilidade do solo. Revista Brasileira de Ciência do Solo, Viçosa, v. 27, n. 4, p. 743-753, jul./ago. 2003.

CULLUM, R. F. et al. Runoff and soil loss form ultra-narrow row cotton plots with and without stiff-grass hedges. Soil and Tillage Research, Amsterdam, v. 93, p. 56-63, 2007.

DECHEN, S. C. F. et al. Gramíneas e leguminosas e seus restos culturais no controle da erosão em Latossolo Roxo. Revista Brasileira de Ciência Solo, Campinas, v. 5, n. 2, p. 133-137, maio/ago. 1981.

ELTZ, F. L. F. et al. Perdas de solo e água por erosão em diferentes sistema $\mathrm{s}$ de manejo e coberturas vegetais em solo laterítico Bruno-Avermelhado distrófico (São Jerônimo) sob chuva natural. Revista Brasileira de Ciência do Solo, Campinas, v. 8, n. 1, p. 117-125, jan./abr. 1984.

FOURNIER, F. The effect of climatic factors on soil erosion estimates of solids transported in suspension in runoff. Association Hydrologic International Public, Hudson, v. 38, p. 1-6, 1956.

GONÇALVES, J. L. M. Conservação do solo. In: GONÇALVES, J. L. M.; STAPE, J. L. (Ed.). Conservação e cultivo de solos para plantações florestais. Piracicaba: IPEF, 2002. p. 47-130.

GUADAGNIN, J. C. et al. Perdas de solo, água e nitrogênio por erosão hídrica em diferentes sistemas de manejo. Revista Brasileira de Ciência do Solo, Viçosa, v. 29, p. 277-286, 2005.

HERNANI, L. C. et al. A erosão e seu impacto. In: MANZATTO, C. V.; FREITAS JUNIOR, E.; PERES, J. R. R. (Ed.). Uso agrícola dos solos brasileiros. Rio de Janeiro: Embrapa Solos, 2002. p. 47-60.

HERNANI, L. C. et al. Sistemas de manejo de solo e perdas de nutrientes e matéria orgânica por erosão. Revista Brasileira de Ciência do Solo, Viçosa, v. 23, n. 1, p. 145-154, jan./mar. 1999.

LEITE, D. et al. Erosão hídrica em um Nitossolo Háplico submetido a diferentes sistemas de manejo sob chuva simulada. I - perdas de solo. Revista Brasileira de Ciência do Solo, Viçosa, v. 28, p. 1033-1044, 2004.

LEVIEN, R.; COGO, N. P. Erosão na cultura do milho em sucessão à aveia preta e pousio descoberto, em preparo convencional e plantio direto, com tração animal e tratorizada. Revista Brasileira de Ciência do Solo, Viçosa, v. 25, n. 3, p. 683-692, jul./set. 2001.

LIMA, J. M. et al. Dispersão do material de solo em água para avaliação indireta da erodibilidade de 
latossolos. Revista Brasileira de Ciência do Solo, Campinas, v. 14, n. 1, p. 85-90, fev. 1990.

LIMA, W. P. Escoamento superficial, perdas de solo e de nutrientes me microparcelas reflorestadas com eucalipto em solos arenosos no município de São Simão, SP. IPEF, Piracicaba, n. 38, p. 5-16, abr. 1988.

LIMA, W. P. Impacto ambiental do eucalipto. 2. ed. São Paulo: Ed. USP, 1996. 301 p.

LOMBARDI NETO, R. Rainfall erosivity: its distribution and relationship with soil loss at Campinas, Brasil. 1977. 53 p. Thesis (Master of Science) - Purdue University, West Lafayette, 1977. MARGOLIS, E. et al. Comportamento de sistemas de cultivo da mandioca em relação à produção e às perdas por erosão. Revista Brasileira de Ciência do Solo, Viçosa, v. 15, n. 1, p. 357-362, jan./abr. 1991.

MARGOLIS, E. et al. Determinação dos fatores da equação universal e perda de solo para as condições de Caruaru-PE. Revista Brasileira de Ciência do Solo, Campinas, v. 9, n. 2, p. 165-169, maio/ago. 1985.

MARTINS, S. G. Erosão hídrica em povoamento de eucalipto sobre solos coesos nos tabuleiros costeiros, ES. 2005. 106 f. Tese (Doutorado em Solos e Nutrição de Plantas) - Universidade Federal de Lavras, Lavras, 2005.

MARTINS, S. G. et al. Perdas de solo e água por erosão hídrica em sistemas florestais na região de Aracruz (ES). Revista Brasileira de Ciência de Solo, Viçosa, v.27, n. 3, p. 395-403, maio/jun. 2003. McGREGOR, K. C. et al. Erodibility factors for loring and lexington soils. Journal of Soil and Water Conservation, Ankeny, v. 24, p. 231-232, 1969.

MEEUWIG, R. O. Sheet erosion on intermountain summer ranges. Ogden: Intermountain Forest, 1970. 25 p.

MINAS GERAIS. Secretaria de Estado de Ciência, Tecnologia e Ensino Superior. Base de dados. Disponível em: <http://www.sectes.mg.gov.br $>$. Acesso em: 8 fev. 2008.

NUNES FILHO, J. et al. Práticas conservacionistas e as perdas por erosão na cultura do milho isolado e consorciado no Sertão do Pajeú (PE). Revista Brasileira de Ciência do Solo, Campinas, v. 14, n. 1, p. 69-72, jan./abr. 1990.

OLIVEIRA, A. H. Erosão hídrica em florestas de eucalipto na região sudeste do Rio Grande do Sul. 2008. 53 f. Dissertação (Mestrado em Ciência do Solo) - Universidade Federal de Lavras, Lavras,
2008.

OLIVEIRA, F. P. Erosão hídrica em áreas florestais no Vale do Rio Doce, Região CentroLeste do Estado de Minas Gerais. 2006. 105 f. Dissertação (Mestrado em Ciência do Solo) Universidade Federal de Lavras, Lavras,2006.

PIRES, L. S. Sistema de manejo de eucalipto e erosão hídrica em Latossolo Vermelho-Amarelo muita argilosa na região de Belo Oriente (MG). 2004. 84 f. Dissertação (Mestrado em Ciência do Solo) - Universidade Federal de Lavras, Lavras, 2004.

PIRES, L. S. et al. Erosão hídrica pós-plantio em florestas de eucalipto na região centro-leste de Minas Gerais. Pesquisa Agropecuária Brasileira, Brasília, v. 41, n. 4, p. 687-695, abr. 2006.

RESENDE, M. Aplicações de Conhecimentos Pedológicos à Conservação de Solos. Informe Agropecuário, Belo Horizonte, MG, v. 11, n. 128, p. 3-18, 1985.

RUFINO, R. L. et al. Influência das práticas de manejo e cobertura vegetal do cafeeiro nas perdas de solo. Revista Brasileira de Ciência Solo, Campinas, v. 9, n. 3, p. 277-280, set./dez. 1985.

SANTOS, D. et al. Queimadas e erosão do solo. Informe Agropecuário, Belo Horizonte, v. 16, p. 62-68, 1992.

SANTOS, D. et al. Perdas de solo e produtividade de pastagens nativas e melhoradas sob diferentes práticas de manejo. Pesquisa Agropecuária Brasileira, Brasília, v. 33, n. 2, p. 183-189, fev. 1998.

SEGANFREDO, M. L. et al. Perdas de solo, água e nutrientes por erosão em sistemas de culturas em plantio direto. Revista Brasileira de Ciência Solo, Viçosa, v. 21, n. 2, p. 287-291, abr./jun. 1997.

SILVA, I. de F. da et al. Influência do cultivo isolado e do consórcio sobre as perdas de solo e água numa terra roxa estruturada. Revista Brasileira de Ciência do Solo, Campinas, v. 13, n. 1, p. 111-115, jan./abr. 1989.

SILVA, L. L. et al. Influência dos resíduos da colheita da floresta de acácia-negra (Acacia mearnsii de wild) sobre as perdas de água e solo. Ciência Florestal, Santa Maria, v.8, n.1, p. 43-53, nov. 1998.

SILVA, M. L. N. et al. Perdas de solo em sistemas de preparo convencional e plantio direto. Informe Agropecuário, Belo Horizonte, v. 16, n. 176, p. 4450, jul. 1992.

SILVA, M. L. N. et al. Tolerância de perdas de solo por erosão hídrica no Vale do Rio Doce na 
região centro-leste do Estado de Minas Gerais. In: REUNIÃO BRASILEIRA DE MANEJO E CONSERVAÇÃO DO SOLO E DA ÁGUA, 14., 2002, Cuiabá. Anais... Cuiabá: SBCS/UFMT, 2002. Não paginado.

SILVA, M. L. N. et al. Avaliação de métodos indiretos de determinação da erodibilidade de latossolos brasileiros. Pesquisa Agropecuária Brasileira, Brasília, v. 35, n. 6, p. 1207-1220, jun. 2000.

SILVA, M. L. N. et al. Relação entre parâmetros da chuva e perdas de solo e determinação da erodibilidade de um latossolo vermelho-escuro em Goiânia (GO). Revista Brasileira de Ciência do Solo, Viçosa, v. 21, n. 1, p. 131-137, jan./mar. 1997. SILVA, M. A. da et al. Avaliação e espacialização da erosividade da chuva no Vale do Rio Doce, região Centro-Leste do Estado de Minas Gerais. Revista Brasileira de Ciência do Solo, Viçosa, v. 34, 2010. no prelo.

VÁSQUEZ-MÉNDEZ, R. et al. Soil erosion and runoff in different vegetation patches from semiarid Central Mexico. Catena, Amsterdam, v. 80, p. 162169, 2010.

VITAL, A. R. T. et al. Efeitos do corte raso de plantação de Eucalyptus sobre o balanço hídrico, a qualidade da água e as perdas de solo e de nutrientes em uma microbacia no Vale do Paraíba, SP. Scientia Forestalis, Piracicaba, n. 55, p. 5-16, jun. 1999.

WISCHMEIER, W. H.; MANNERING，J. V. Relation of soil properties to its erodibility. Soil Science Society of America Proceedings, Madison, v. 33, n. 1, p. 131-137, Jan./Feb. 1969. 